\title{
Amiloride reduces portal hypertension in rat liver cirrhosis
}

\author{
Christian J Steib, ${ }^{1}$ Martin Hennenberg, ${ }^{2}$ Frigga Beitinger, ${ }^{3}$ Anna C Hartmann, ${ }^{1}$ \\ Markus Bystron, ${ }^{4}$ Enrico N De Toni, ${ }^{1}$ Alexander L Gerbes ${ }^{1}$
}

${ }^{1}$ Department of Medicine II

(Gastroenterology and Hepatology), Liver Center Munich, University of Munich Grosshadern, Munich, Germany ${ }^{2}$ Department of Urology, University of

Munich-Grosshadern, Munich, Germany

${ }^{3}$ Institute of Pathology, University of Munich, Munich, Germany

${ }^{4}$ Department of Medicine II, Klinikum Memmingen, Memmingen, Germany

\section{Correspondence to} Dr Christian J Steib, Klinikum Grosshadern - Department of Medicine II, Liver Center Munich (LCM), Ludwig-Maximilians University, Marchioninistrasse 15. Munich 81377, Germany: christian.steib@med. uni-muenchen.de

Revised 29 December 2009 Accepted 31 January 2010

\section{ABSTRACT}

Objective This study aimed to investigate the effect of amiloride on portal hypertension. Amiloride is known to inhibit $\mathrm{Na}^{+} / \mathrm{H}^{+}$exchangers on activated hepatic stellate cells.

Methods Liver cirrhosis in rats was induced by bile duct ligation (BDL) or thioacetamide (TAA) administration. The effects of zymosan for Kupffer cell (KC) activation or a thromboxane (TX) analogue (U46619) were tested in isolated perfused livers of cirrhotic rats and in vivo. Downstream mechanisms were investigated using Rho kinase inhibitor (Y-27632) or amiloride. Acute and chronic effects of amiloride and canrenoate on portal pressure were compared in perfused livers and in vivo. $\mathrm{TXB}_{2}$ efflux was measured by ELISA. The phosphorylation state of moesin (p-moesin) as an indicator of Rho kinase activity and expression of the thromboxane synthase were assessed by western blot analyses. The activity of hepatic stellate cells was analysed by western blot and staining for $\alpha$-smooth muscle actin ( $\alpha$-SMA).

Results In BDL rats, $\mathrm{KC}$ activation via zymosan increased portal pressure. This was attenuated by the Rho kinase inhibitor Y-27632. Increased thromboxane efflux following zymosan infusion remained unaltered by Y-27632. The infusion of amiloride attenuated zymosanand U46619-induced increases in portal perfusion pressure. In vivo, direct administration of amiloride, but not of canrenoate, lowered portal pressure. In TAA and $\mathrm{BDL}$ rats, treatment with amiloride for 3 days reduced basal portal pressure and $\mathrm{KC}$-induced increases in portal pressure whereas canrenoate had no effect. In livers of amiloride-treated animals, the phosphorylation state of moesin and the number of $\alpha$-SMA positive cells were reduced.

Conclusions Amiloride lowers portal pressure in rat liver cirrhosis by inhibition of intrahepatic vasocontraction. Therefore, patients with cirrhosis and portal hypertension may benefit from amiloride therapy.

\section{INTRODUCTION}

Variceal bleeding represents a life-threatening complication of portal hypertension in chronic liver diseases. Mortality is, at first, closely connected to control of acute and then of recurrent bleeding, which occurs in up to $40 \%$ of patients. ${ }^{1-3}$ Sudden and uncontrolled increases in portal pressure are responsible for variceal bleeding in patients with liver cirrhosis and portal hypertension. ${ }^{4}$ In cirrhotic livers, impairment of the intrahepatic microcirculation is the result of both structural changes and an increased intrahepatic vascular tone..$^{5-7}$

Alterations of intrahepatic vascular tone in liver cirrhosis originate from an upregulation of vaso- constrictors, ${ }^{8}$ including thromboxane (TX) $\mathrm{A}_{2},{ }^{9} 10$ and a decrease in vasodilators. ${ }^{11}$ Activation of Kupffer cells (KCs) results in the formation of $\mathrm{TXA}_{2}$, which increases portal pressure. ${ }^{10}{ }^{12-14}$

Postulated contractile cells in the liver are activated hepatic stellate cells (HSCs) and myofibroblasts. ${ }^{5}$ Contraction mechanisms of these cells are under the control of $\mathrm{Ca}^{2+}$-dependent and $\mathrm{Ca}^{2+}$-independent pathways. Both pathways are upregulated in the cirrhotic liver by activation and excessive proliferation of HSC. $\mathrm{Ca}^{2+}$-independent pathways include activation of Rho kinase by vasoconstrictors; these pathways lead to contraction of hepatic stellate cells and myofibroblasts. ${ }^{15} 16$ Indeed, inhibition of Rho kinase in the intrahepatic microvasculature of cirrhotic livers causes substantial decreases in intrahepatic vascular resistance and portal pressure. ${ }^{17-19}$

Several in vivo and in vitro studies, which focussed on the pathomechanisms of fibrogenesis, identified the potential of the $\mathrm{Na}^{+} / \mathrm{H}^{+}$exchanger amiloride to inhibit the activity of hepatic stellate cells. ${ }^{20}{ }^{21}$ However, the effects of amiloride or other inhibitors of $\mathrm{Na}^{+} / \mathrm{H}^{+}$exchangers on increased intrahepatic vascular resistance or on portal hypertension in cirrhosis have not been tested. The present study investigated the effects of amiloride on portal pressure in rat liver cirrhosis.

\section{MATERIALS AND METHODS}

\section{Animals}

All animals were ethically treated according to the criteria of the National Academy of Sciences published by the National Institutes of Health and according to legal requirements in Germany. All animal experiments were approved by the local government (Regierung von Oberbayern, Munich, Germany) and were reported to the responsible authorities every 3 months.

Induction of liver fibrosis by bile duct ligation Male Sprague-Dawley rats (180-200 g; Charles River, Sulzfeld, Germany) were anaesthetised by intraperitoneal pentobarbital injection $(75 \mathrm{mg} / \mathrm{kg}$ body weight (b.w.)). After a midline laparotomy was performed, the common bile duct was ligated twice with 3-0 silk and cut between the two ligations. ${ }^{10} 19$ Sham-operated rats were subjected to laparotomy without bile duct ligation (BDL). Liver perfusion with Krebs-Henseleit buffer and in vivo experiments were performed 4 weeks after the operation, as described below. At this time, the rats had elevated values in liver function tests (alkaline phosphatase, $\gamma$ glutamyltransferase, bilirubin, aspartate aminotransferase and alanine aminotransferase, see table 1). 
Table 1 Serum parameters from normal animals, bile duct ligated (BDL) animals, thioacetamide administered (TAA) or TAA animals with amiloride $(0.1 \mathrm{mg} / \mathrm{kg} \mathrm{b.} \mathrm{w.)}$ or canrenoate $(10 \mathrm{mg} / \mathrm{kg} \mathrm{b.} \mathrm{w.)} \mathrm{pre-treatment}$

\begin{tabular}{|c|c|c|c|c|c|}
\hline & Normal & BDL & TAA & TAA+amiloride pre-treatment & TAA+canrenoate pre-treatment \\
\hline Sodium (mmol/l) & $142 \pm 4.2$ & $137 \pm 4.7$ & $138 \pm 6.3$ & $139 \pm 5.6$ & $137 \pm 6.4$ \\
\hline Potassium (mmol/l) & $4.2 \pm 0.3$ & $4.3 \pm 0.8$ & $4.1 \pm 0.7$ & $4.8 \pm 0.5$ & $4.5 \pm 0.7$ \\
\hline Creatinine (mg/dl) & $0.2 \pm 0.1$ & $0.3 \pm 0.1$ & $0.4 \pm 0.1$ & $0.4 \pm 0.2$ & $0.3 \pm 0.2$ \\
\hline Aspartate transaminase (U/I) & $45 \pm 8$ & $98 \pm 17^{*}$ & $132 \pm 12^{*}$ & $124 \pm 18 *$ & $129 \pm 15^{*}$ \\
\hline Alanine aminotransferase (U/I) & $34 \pm 5$ & $75 \pm 12 \dagger$ & $139 \pm 5 \dagger$ & $127 \pm 5 \dagger$ & $135 \pm 5 \dagger$ \\
\hline$\gamma$-Glutamyl transferase (U/I) & $1.3 \pm 0.4$ & $21 \pm 1.7 \ddagger$ & $18 \pm 1.9 \neq$ & $10 \pm 1.5 \ddagger$ & $21 \pm 1.7 \ddagger$ \\
\hline
\end{tabular}

Bilirubin $(+p<0.05)$ increased only in BDL animals; AST, ALT and $\gamma$ GT in TAA and BDL animals $\left({ }^{*} p<0.05, \dagger p<0.05, \neq p<0.05\right)$.

\section{Induction of liver cirrhosis by thioacetamide}

Rats were treated with thioacetamide (TAA) for 18 weeks. ${ }^{22}$ In brief, male Sprague-Dawley rats (Charles River) between 200 and $250 \mathrm{~g}$ were weighed once per week. A starting dose of $0.3 \%$ TAA was added to drinking water. If a body weight variation of $20 \%$ or more from 1 week to the next was determined, the dose of TAA was adapted as described previously. ${ }^{22}$

\section{In situ rat liver perfusion}

Rats were anaesthetised with an intraperitoneal injection of sodium pentobarbital $(50 \mathrm{mg} / \mathrm{kg}$ b.w.). After incision of the abdominal wall, blood was taken from the inferior vena cava (about 3-4 ml) in order to determine serum parameters. Subsequently, the portal vein was cannulated with an intravenous 14-gauge Teflon catheter, and the liver was perfused at a constant flow rate. The inferior vena cava was cannulated via the right atrium and ligated above the right renal vein. In all experiments, livers were perfused with Krebs-Henseleit solution $\left(\mathrm{pH} 7.4,37^{\circ} \mathrm{C}\right)$ in a non-recirculating fashion. The perfusion buffer was gassed with a mixture of $95 \% \mathrm{O}_{2}$ and $5 \% \mathrm{CO}_{2}$ using an oxygenator. ${ }^{23}$ Portal perfusion pressure was monitored continuously. The bile duct was cannulated with a polyethylene tube (PE10) to monitor bile flow in both sham-operated and non-operated animals. The liver was allowed to stabilise for $25 \mathrm{~min}$ before any substances were added. During this initial $25 \mathrm{~min}$ stabilisation period, the criteria for liver viability included stable perfusion pressure and lactate dehydrogenase $(\mathrm{LDH})$ efflux rates $<5 \mathrm{mU} / \mathrm{min} \times \mathrm{g}$ liver. $\mathrm{LDH}$ activity was analysed as previously reported. ${ }^{24}$ If any of the criteria for viability were not satisfied, the sample was discarded.

\section{Kupffer cell activation and blockade of Rho kinase by Y-27632}

KCs were activated by the infusion of cell wall particles from Saccharomyces cerevisiae (zymosan A, $\mathrm{n}=5$ ). Zymosan was prepared and infused as described previously in minutes 40-46 after starting perfusion experiments $(150 \mu \mathrm{g} / \mathrm{ml}))^{23} 25$ and combined with Y-27632 or solvent (water) from minutes 25 to 55. In control experiments, perfusion was performed only with Krebs-Henseleit buffer over $100 \mathrm{~min}(\mathrm{n}=5)$. Infusion with Y$27632(10 \mu \mathrm{mol} / 1$, during minutes 25 to $55, \mathrm{n}=5)$ was used to block Rho kinase-mediated contraction of hepatic stellate cells and myofibroblasts. ${ }^{19} 26$

\section{Acute amiloride effects in liver perfusion}

In a further set of experiments, $\mathrm{KC}$ activation by zymosan $(150 \mu \mathrm{g} / \mathrm{ml}$, during minute 40-46 after starting perfusion experiments, $\mathrm{n}=5$ ) was combined with amiloride infusion $(100 \mu \mathrm{mol} / 1$, minute 25 to $55, \mathrm{n}=5)$. In another set of experiments, the thromboxane $A_{2}$ agonist $U 46619$ ( $0.1 \mu \mathrm{mol} / 1$, minute
40 to $46, n=5$ ) was infused with or without amiloride (100 $\mu \mathrm{mol} / 1$, minute 25 to $55, \mathrm{n}=5)$. The diuretic amiloride has been shown to block hepatic stellate cells in in vivo and in vitro studies for fibrogenesis. ${ }^{20}$

\section{In vivo measurements of portal pressure}

Body weight was determined immediately prior to each experiment. Surgery (4 weeks after BDL or 18 weeks after TAA) was begun after anaesthesia, using an intra-peritoneal injection of sodium pentobarbital (50 mg/kg b.w.). Arterial blood pressure was continuously monitored via a carotid catheter. Laparotomy was performed and a PE tube $(23 \mathrm{G}, 0.6 \times 30 \mathrm{~mm})$ was inserted into the ileocolic vein and advanced to the confluence of the portal vein and splenic vein. ${ }^{10} 27$ This cannula was used for the simultaneous infusion of zymosan and the registration of portal pressure, as described earlier, ${ }^{10} 27$ via a transducer system (Sirecust 404; Siemens, Munich, Germany, and Transducer Gabarith from Becton Dickinson, Singapore). This transducer has linearity from $<2 \%$ or $1 \mathrm{~mm} \mathrm{Hg}$ and is approved for the clinical use in humans (information from the manual supplied by Becton Dickinson).

\section{Acute effects of amiloride on zymosan-induced increase} of portal pressure in vivo

Four weeks after BDL, a bolus of amiloride $(0.25 \mathrm{mg} / \mathrm{kg}$ b.w.) was injected into the femoral vein 5 min before intraportal zymosan application $(3.2 \mathrm{mg} / \mathrm{min}$, from minute 0 to 6$)$ to investigate the effect of amiloride on $\mathrm{KC}$-dependent increase of portal pressure $(n=7)$.

\section{Acute effects of amiloride and canrenoate on basal portal} pressure in vivo

Portal pressure and systemic blood pressure were monitored continuously over the stabilisation period of $10 \mathrm{~min}$ and the following $40 \mathrm{~min}$. After the stabilisation period, a bolus of amiloride (0.1 mg/kg b.w., $\mathrm{n}=4 ; 0.25 \mathrm{mg} / \mathrm{kg}$ b.w., $\mathrm{n}=4 ; 0.5 \mathrm{mg} /$ kg b.w., $\mathrm{n}=4$ ) or canrenoate (1 mg/kg b.w., $\mathrm{n}=4 ; 2.5 \mathrm{mg} / \mathrm{kg}$ b.w., $\mathrm{n}=4 ; 5 \mathrm{mg} / \mathrm{kg}$ b.w., $\mathrm{n}=4$ ) was infused into the femoral vein to delineate the potential of amiloride or canrenoate to lower basal portal pressure.

Effects of treatment with amiloride or canrenoate for 3 days on portal pressure

Amiloride (0.1 mg/kg b.w., $\mathrm{n}=7$ ), canrenoate $(5 \mathrm{mg} / \mathrm{kg}$ b.w., $\mathrm{n}=7$ ) or vehicle (water) were applied by subcutaneous injection once a day during the last 3 days of 4 weeks of BDL or 18 weeks of TAA administration ( $n=7 /$ group). Afterwards, KCs were activated in vivo by zymosan (intraportal application, $3.2 \mathrm{mg} /$ min, from minute 0 to 6 ). 


\section{Measurements of serum parameters}

Serum parameters were measured by an Olympus AU2700 analyser (Olympus Germany $\mathrm{GmbH}$, Hamburg), according to standard tests based on the recommendations of the International Federation of Clinical Chemistry (IFCC).

\section{ELISA}

The levels of $\mathrm{TXB}_{2}$ (the stable degradation product of $\mathrm{TXA}_{2}$ ) produced by the livers were quantified by measuring their release into the perfusate. Levels of $\mathrm{TXB}_{2}$ were measured in duplicate using an enzyme immunoassay (Assay Design, Ann Arbour, Michigan, USA). This assay has an intra-assay coefficient of variation of $3.6 \%, 4.0 \%$ and $1.6 \%$ and an inter-assay coefficient of variation of $7.6 \%, 3.6 \%$ and $6.2 \%$ for low, medium and high values (data from the manual). Furthermore, the test has a cross-reactivity $<0.01 \%$ for prostaglandin $D_{2}, E_{2}, F_{1 \alpha}$ and $\mathrm{F}_{2 \alpha}$.

\section{Histological evaluation, staining for $\alpha$-smooth muscle actin, and TUNEL assay}

Liver tissue was fixed in 4\% buffered formalin, dehydrated in graded ethanol and embedded in paraffin by standard methods. Longitudinal sections, $4 \mu \mathrm{m}$ thick, were stained with $\mathrm{H} \& \mathrm{E}$ (haematoxylin/eosin) and Elastica van Gieson (EvG) according to standard procedures. Immunohistochemistry was performed using an anti-actin antibody (Millipore, Billerica, Massachusetts, USA), dilution 1:300, and the detection system Histofine Simple Stain MAX PO MULTI (Medac, Wesel, Germany) ( $n=7$ per group). The terminal deoxynucleotidyl transferase-mediated deoxyuridine triphosphate nick-end labelling (TUNEL) method was performed using the Apop Tag Peroxidase Detection Kit (Millipore, Schwalbach, Germany) according to the manufacturer's instructions ( $\mathrm{n}=7$ per group).

\section{Western blot analyses for phospho-moesin, total moesin, and $\alpha$-smooth muscle actin}

To assess the effect of amiloride on Rho kinase activity in BDL and TAA rats, western blot analyses for phospho-moesin (threonine 558) and total moesin were performed according to standard procedures. Additionally, the expression of the thromboxane synthase and the content of $\alpha$-SMA were measured. Briefly, after SDS-PAGE and blotting, proteins transferred to the membrane were detected by incubation with primary antibodies (anti-phospho-moesin, anti-moesin and anti- $\alpha$-SMA; Santa Cruz Biotechnology, Santa Cruz, California,USA; and anti-thromboxane synthase; Cayman Chemical, Ann Arbor, Michigan, USA), followed by incubation with a horseradish peroxidase (HRP)-conjugated secondary antibody (Santa Cruz Biotechnology). Bands were visualised using a chemiluminescent detection kit (ECL Plus; Amersham Pharmacia, Uppsala, Sweden). $\beta$-Actin was used as an internal control and detected with an appropriate anti- $\beta$-actin antibody (Millipore, Billerica, USA). The computed quantitative analyses were performed with ImageJ (NIH, USA).

\section{Drugs and reagents}

Zymosan, Y-27632, amiloride and canreonate were obtained from Sigma Aldrich (Munich, Germany). Amiloride and canrenoate were handled in the dark as far as possible and dissolved in water. Water was heated to below $50^{\circ} \mathrm{C}$ to dissolve amiloride; this was not necessary for canrenoate. U46619 was from Cayman Chemical (Ann Arbour, USA) and dissolved in DMSO.

\section{Statistical analysis}

All data are expressed as means \pm SD. Statistical analyses were performed using ANOVA and the Student t test, where appropriate. A p value $<0.05$ was considered to be statistically significant. Statistical preparation and analyses were performed in collaboration with the Institute for Biometrics and Epidemiology of the University of Munich (IBE, Munich, Germany).

\section{RESULTS \\ KC-dependent portal pressure increase via thromboxane $A_{2}$ and Rho kinase}

All rats had developed ascites and portal hypertension 4 weeks after BDL, as determined by an increase in portal pressure measured in vivo immediately prior to the start of liver perfusion. As expected, spleen weight had also increased in the rats $(1.5 \pm 0.2 \mathrm{~g}$ vs $0.4 \pm 0.1 \mathrm{~g})$. In control experiments, portal perfusion pressure was found to be constant during $100 \mathrm{~min}$ of liver perfusion (figure 1A). Activation of KCs by zymosan markedly increased portal perfusion pressure from $11.3 \pm 1.3 \mathrm{~cm} \mathrm{H}_{2} \mathrm{O}$ to $24.8 \pm 1.7 \mathrm{~cm} \mathrm{H}_{2} \mathrm{O}$ (figure 1A). The Rho kinase inhibitor Y-27632 significantly attenuated this zymosan-induced increase of portal perfusion pressure about $60 \%$ (figure $1 \mathrm{~A}$ ). Activation of KCs was paralleled by an increased efflux of $\mathrm{TXB}_{2}$, the stable degradation product of $\mathrm{TXA}_{2}$ (figure $1 \mathrm{~B}$ ). The enhanced $\mathrm{TXB}_{2}$ efflux was not altered by Y-27632 (figure 1B).

\section{Attenuation of portal hypertension by amiloride}

The zymosan-induced increase of portal perfusion pressure following $\mathrm{KC}$ activation was reduced by infusion of amiloride by about $50 \%$ (figure $2 \mathrm{~A}$ ) in rats with BDL-induced liver fibrosis. Similar to zymosan, the TX analogue U46619 increased portal perfusion pressure (figure 2A). Again, this increase was attenuated by infusion of amiloride by about $50 \%$ (figure $2 \mathrm{~A}$ ). $\mathrm{pH}$ was measured in the effluent perfusate, but not affected by infusion of amiloride (data not shown). These effects were confirmed by measurement of portal pressure in vivo. Infusion of amiloride in vivo attenuated the acute portal pressure increase after zymosan-induced $\mathrm{KC}$ activation in $\mathrm{BDL}$ rats (figure $2 \mathrm{~B}$ ). The infusion of zymosan lowered systemic mean arterial pressure in both groups (table 2).

\section{Dose response for amiloride and canrenoate on portal pressure in vivo}

We next assessed the potential of amiloride and canrenoate to lower basal portal pressure of BDL rats in vivo without zymosan challenge. Similar to amiloride, canrenone has been found to block HSC activity. Both canrenoate and spironolactone are prodrugs of the active metabolite canrenone. Amiloride lowered portal pressure at each dose tested (figure $3 \mathrm{~A}$ ). This amilorideinduced decrease of portal pressure was dose-dependent (figure $3 \mathrm{~A}$ ). In contrast, canrenoate affected portal pressure only slightly and at high doses, although this was not statistically significant (figure 3B). Neither systemic mean arterial pressure (table 2) nor heart rate was affected by either compound in any treatment group (data not shown).

\section{Effects of amiloride and canrenoate treatment for 3 days in} BDL-induced and TAA-induced cirrhosis

Using the animal model of BDL- and TAA-induced cirrhosis, we performed studies to examine the mechanisms underlying the effects of amiloride. All rats had developed the histological picture of liver cirrhosis, elevated values in liver function test (table 1), increased spleen weight $(1.5 \pm 0.2$ vs $0.4 \pm 0.1 \mathrm{~g})$ and ascites. In vivo, the basal portal pressure was higher in rats 
A
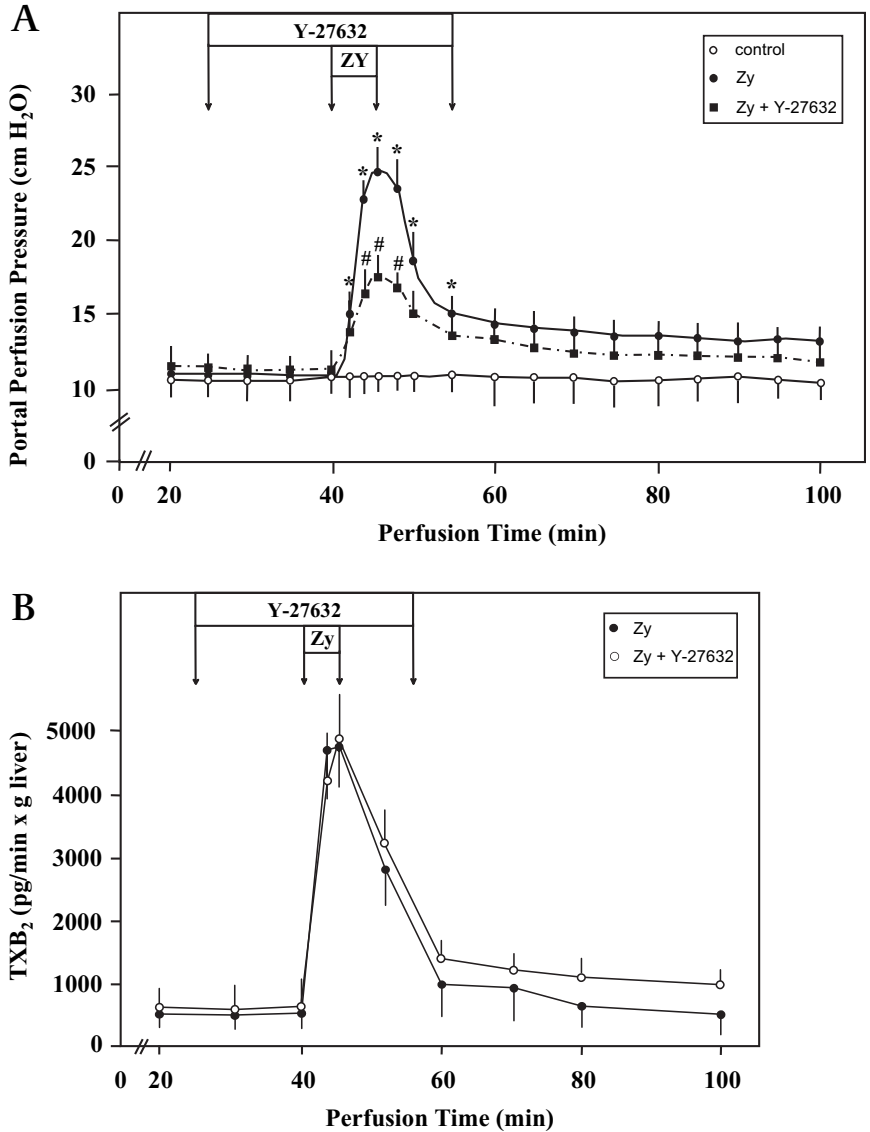

Figure 1 Rho kinase-dependent increase in portal perfusion pressure following Kupffer cell $(\mathrm{KC})$ activation. Data are expressed as mean \pm SD. (A) KC activation by zymosan A $(\bullet, Z y, 150 \mu \mathrm{g} / \mathrm{ml}$, minute 40 to 46 , $n=5) 4$ weeks after bile duct ligation (BDL) increased portal perfusion pressure $\left({ }^{*} p<0.05\right)$ compared to controls $(0, n=5)$. Additional infusion of Rho kinase inhibitor Y-27632 ( $\square, 10 \mu \mathrm{mol} / \mathrm{l}$, minute 25 to $55, \mathrm{n}=5$ ) attenuated this portal perfusion pressure increase $(\# p<0.05)$. (B) The portal perfusion pressure increase by zymosan was parallelled by efflux of thromboxane $B_{2}\left(\bullet, T X B_{2}, n=5\right)$, the stable degradation product of $\mathrm{TXA}_{2}$. Y-27632 (o, $10 \mu \mathrm{mol} / \mathrm{l}$, minute 25 to $\left.55, \mathrm{n}=5\right)$ did not alter efflux of $\mathrm{TXB}_{2}$ into perfusate.

4 weeks after BDL or with TAA-induced liver cirrhosis than in non-cirrhotic control rats. Amiloride administration for 3 days reduced both basal portal pressure and zymosan-induced maximal portal pressure in BDL and TAA rats by about $30 \%$ (figure $4 \mathrm{~A}, \mathrm{~B}$ ). In contrast to amiloride, the treatment of TAA rats with canrenoate did not affect basal portal pressure or zymosaninduced maximal portal pressure (figure 4A,B). Portal pressure values at the end of the experiments were comparable to initial values (figure 4C). Heart rate (data not shown), systemic mean arterial pressure (table 2) and grade of cirrhosis (data not shown) were not affected by treatment with amiloride or canrenoate. Western blot analyses showed a reduced content of phosphorylated moesin ( $p$-moesin) in livers of amiloride-treated BDL and TAA rats compared to livers of vehicle-treated BDL or TAA rats, while the content of total moesin (t-moesin) was not affected (figure $5 \mathrm{~A}, \mathrm{~B}$ ). This observation was confirmed by quantification of western blots (figure $5 \mathrm{~A}, \mathrm{~B}$ ). In contrast, the expression of thromboxane synthase was not influenced by amiloride treatment (figure 5C) in TAA-induced cirrhosis. To evaluate the effect of amiloride treatment on activity of the hepatic stellate cells, immunohistological stainings of $\boldsymbol{\alpha}$-SMA were performed (figure $6 \mathrm{~A})$. Analysis of these stainings showed a decrease in the number
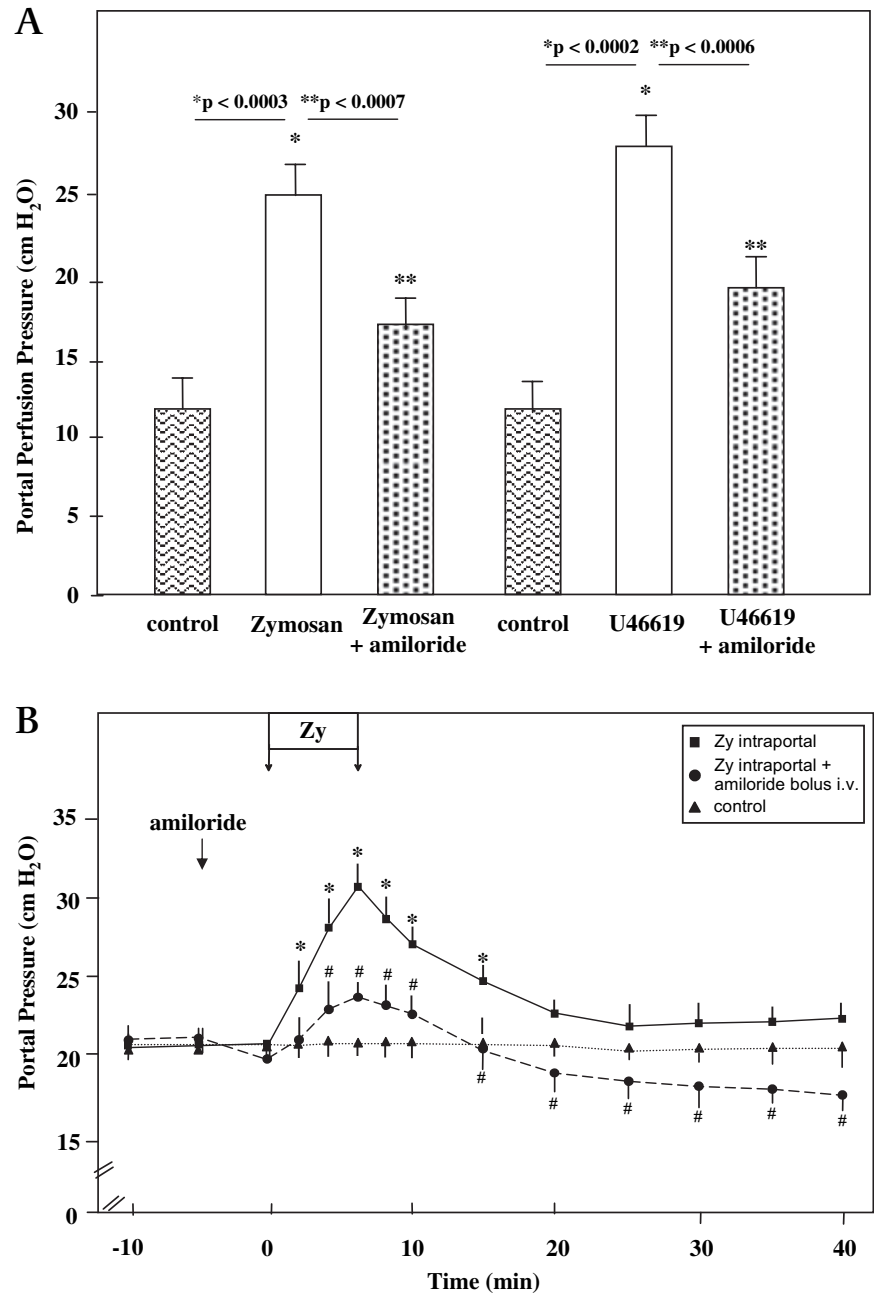

Figure 2 Amiloride attenuates portal perfusion pressure increase. Data are expressed as mean \pm SD. These experiments were performed 4 weeks after BDL. (A) Liver perfusion experiments. Maximal increase of portal perfusion pressure following zymosan $A(150 \mu \mathrm{g} / \mathrm{ml}$, minute 40 to $46, n=5)$ was reduced by amiloride infusion $(100 \mu \mathrm{mol} / \mathrm{l}$, minute 25 to $55, n=5)$. The thromboxane $A_{2}$ analogue $U 46619(0.1 \mu \mathrm{mol} / \mathrm{l}$, minute 40 to $46, n=5$ ) increased portal perfusion pressure, which was lowered by amiloride infusion $\left(100 \mu \mathrm{mol} / \mathrm{l}\right.$, minute 25 to $\left.55, \mathrm{n}=5,{ }^{* *} \mathrm{p}<0.0006\right)$. (B) In vivo experiments. Bolus infusion of amiloride into the femoral vein $(\bullet, 0.25 \mathrm{mg} / \mathrm{kg}$ b.w., minute $-5, \mathrm{n}=5, \# \mathrm{p}<0.05)$ attenuated portal pressure increase in vivo following Kupffer cell activation by zymosan ( , Zy intraportal, $3.2 \mathrm{mg} / \mathrm{min}$, minute $0-6, n=7,{ }^{*} p<0.05$ ). Control experiments with a stabilisation period of 10 min and an observation period of $40 \mathrm{~min}$ afterwards showed almost no change in portal pressure $(\boldsymbol{\Delta}, \mathrm{n}=4)$.

of $\alpha$-SMA positive cells in the amiloride-treated group of TAA rats compared to the group of TAA rats with vehicle administration (figure 6A). These findings were substantiated by western blot analyses which showed a reduced content of $\alpha$ SMA following amiloride treatment (figure $6 \mathrm{~B}$ ). To investigate whether processes of apoptosis were involved in the reduction of the $\alpha$-SMA positive cells, a TUNEL assay has been performed. The analysis of this staining demonstrated that there was no difference in the number of apoptotic cells between vehicletreated and amiloride-treated animals (figure 7).

\section{DISCUSSION}

This study describes the effects and underlying mechanisms of amiloride on portal hypertension in different animal models of 
Table 2 Mean arterial pressure during in vivo portal pressure measurements

\begin{tabular}{lcrc}
\hline Mean arterial pressure (mm $\mathbf{~ g g})$ & minute $\mathbf{- 5}$ & minute $\mathbf{6}$ & minute $\mathbf{4 0}$ \\
\hline BDL & & & \\
Amiloride $0.1 \mathrm{mg} / \mathrm{kg}$ b.w. & $109 \pm 12$ & $115 \pm 14$ & $114 \pm 12$ \\
Amiloride $0.25 \mathrm{mg} / \mathrm{kg}$ b.w. & $117 \pm 15$ & $110 \pm 12$ & $117 \pm 14$ \\
Amiloride $0.5 \mathrm{mg} / \mathrm{kg}$ b.w. & $103 \pm 15$ & $105 \pm 10$ & $107 \pm 11$ \\
Canrenoate $2.5 \mathrm{mg} / \mathrm{kg} \mathrm{b.w.}$ & $105 \pm 14$ & $98 \pm 12$ & $104 \pm 10$ \\
Canrenoate $5 \mathrm{mg} / \mathrm{kg}$ b.w. & $108 \pm 12$ & $105 \pm 14$ & $108 \pm 12$ \\
Canrenoate $10 \mathrm{mg} / \mathrm{kg}$ b.w. & $102 \pm 14$ & $110 \pm 12$ & $112 \pm 14$ \\
Zymosan & $109 \pm 12$ & $84 \pm 15$ & $67 \pm 12 \dagger$ \\
Zymosan + amiloride $0.25 \mathrm{mg} / \mathrm{kg}$ b.w. & $104 \pm 15$ & $81 \pm 14$ & $64 \pm 12 \dagger$
\end{tabular}

TAA

\section{Zymosan}

Zymosan + canrenoate pre-treatment

$124 \pm 12$

$115 \pm 11$

$85 \pm 9 *$

Zymosan + amiloride pre-treatment

$121 \pm 14$

$110 \pm 8$

$78 \pm 7^{*}$

$115 \pm 11$

$97 \pm 8$

$75 \pm 5^{*}$

The mean arterial pressure did not differ between bile duct ligated (BDL) and thioacetamide administered animals (TAA). Mean arterial pressure decreased by Kupffer cell activation via zymosan $(150 \mu \mathrm{g} / \mathrm{ml})$ from minute 0 to 6 in the BDL animals with or without immediate amiloride treatement $\left({ }^{*} \mathrm{p}<0.05\right)$. Mean arterial pressure also decreased in the TAA animals by zymosan $(150 \mu \mathrm{g} / \mathrm{ml})$ administration $(\dagger p<0.05)$, but the mean arterial pressure was not influenced by canrenoate $(10 \mathrm{mg} / \mathrm{kg}$ b.w.) or amiloride $(0.1 \mathrm{mg} / \mathrm{kg} \mathrm{b.w.)}$ pre-treatment

cirrhosis. We observed a reduction in intrahepatic vascular resistance and portal pressure by amiloride. Although amiloride can be applied for the treatment of cirrhosis, the current study is, to our knowledge, the first investigation of the effects of amiloride on portal hypertension. Most important among our findings were that (1) KC activation increased the portal pressure via $\mathrm{TXA}_{2}$ and the consecutive intrahepatic vasoconstriction by Rho kinase; (2) blockade of hepatic stellate cells by amiloride lowered portal pressure dose-dependently and was more effective than canrenoate; and (3) amiloride reduced both basal portal pressure and acute $\mathrm{KC}$-dependent portal pressure increases in rat liver cirrhosis These results were obtained using in situ perfused livers and confirmed by in vivo studies in two different animal models of cirrhosis. The diagnosis of cirrhosis in the BDL and TAA rats was made based on serum parameters, the presence of ascites, changes in liver histology and elevated portal pressure in vivo.

\section{Kupffer cell activation and inhibition of Rho kinase}

Our initial set of experiments demonstrated that the activation of KCs by infusion of zymosan increased portal perfusion pressure in livers 4 weeks after BDL. This confirmed findings in our previous studies. ${ }^{10}$ Interestingly, the addition of the Rho kinase inhibitor Y-27632 prevented this KC-dependent increase in portal perfusion pressure. Rho kinase has been described as an important mediator of vasoconstriction in hepatic stellate cells and intrahepatic myofibroblasts. ${ }^{15} 19$ Kupffer cell activation resulted in thromboxane production, which was not influenced by the Rho kinase inhibitor, while portal pressure was significantly reduced by the Rho kinase inhibitor. Indeed, Rho kinase in intrahepatic microvasculature may represent an attractive target for therapies of portal hypertension. Infusion of a Rho kinase inhibitor results in dramatic decreases of mean arterial pressure and systemic vascular resistance ${ }^{15} 18$. Therefore, alternatives to block intrahepatic vasoconstriction are needed.

Reduction of portal pressure by amiloride

Amiloride is routinely used as a diuretic and has been shown to prevent fibrogenesis effectively in vitro and in vivo. ${ }^{20}$ The in vitro data suggest that amiloride inhibited activation of the
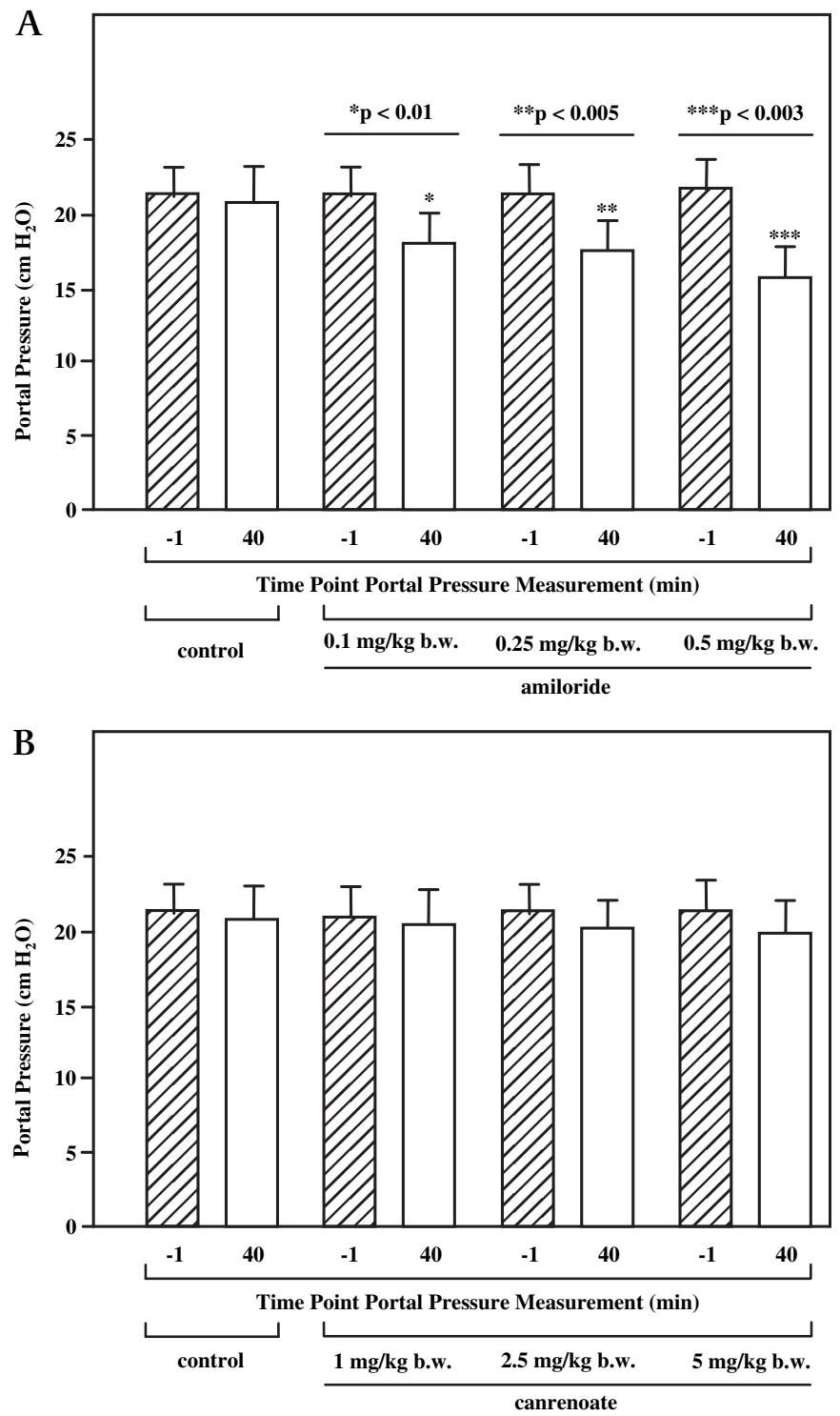

Figure 3 Dose-response curves for acute effects of amiloride and canrenoate in vivo. Data are expressed as mean $\pm S D$. These experiments were performed 4 weeks after bile duct ligation (BDL). (A) Bolus infusion of amiloride in three different doses (minute 0 , each $n=4$ ) into the femoral vein showed a reduction of portal pressure in vivo after 40 min compared to portal pressure at the end of the stabilisation period in the same animals (minute -1 ). (B) In contrast, the bolus infusion of canrenoate in three different concentrations (minute 0 , each $n=4$ ) into the femoral vein showed a slight, but not significant, reduction of portal pressure in vivo after 40 min compared to portal pressure at the end of the stabilisation period (minute -1 ).

$\mathrm{Na}^{+} / \mathrm{H}^{+}$exchanger on isolated hepatic stellate cells. Besides fibrogenesis, activated hepatic stellate cells mediate contraction of the intrahepatic vasculature. We therefore tested the hypothesis that amiloride attenuates intrahepatic vascular resistance and portal pressure due to decreased HSC contraction in intrahepatic microvasculature by $\mathrm{KC}$-derived vasoconstrictors. Indeed, amiloride attenuated increases of portal perfusion pressure following direct KC activation by zymosan or administration of the thromboxane analogue U46619. We assume that the effects of amiloride in our study can be attributed to the inhibition of $\mathrm{Na}^{+} / \mathrm{H}^{+}$exchangers, because unspecific actions (eg, inhibition of the adrenergic system) require higher doses than used here. ${ }^{28}$ Furthermore, $\mathrm{pH}$ remained unchanged in effluent 
Figure 4 Amiloride but not canrenoate treatment for 3 days reduced portal pressure in vivo. Data are expressed as mean $\pm S D$. Amiloride ( $0.1 \mathrm{mg} / \mathrm{kg}$ b.w., $\mathrm{n}=7$ per group), canrenoate $(5 \mathrm{mg} / \mathrm{kg}$ b.w., $\mathrm{n}=7$ per group) or the vehicle for both (water, $\mathrm{n}=7$ per group) was given subcutaneously during the last 3 days of bile duct ligation (BDL) for 4 weeks or thioacetamide (TAA) administration period of 18 weeks. (A) Basal portal pressure (minute -5 ) was much higher in BDL and TAA animals than in control animals $\left({ }^{*} p<0.0001\right)$ and was reduced by amiloride pre-treatment $(+p<0.006$, treated with the vehicle. In contrast, canrenoate pre-treatment did not alter portal pressure in vivo in TAA animals. (B) Maximal portal pressure following Kupffer cell activation by zymosan (Zy intraportal, $3.2 \mathrm{mg} / \mathrm{min}$, minute $0-6,+$ $+p<0.002$, \# \#p<0.004) was attenuated by amiloride pre-treatment in comparison to the vehicle group. Canrenoate did not alter maximal portal pressure. (C) At the end of the experiments (minute 40), portal pressure decreased to close to initial values (minute -5 ) and was still reduced in the amiloride pre-treatment group. $\# p<0.005)$ compared to animals
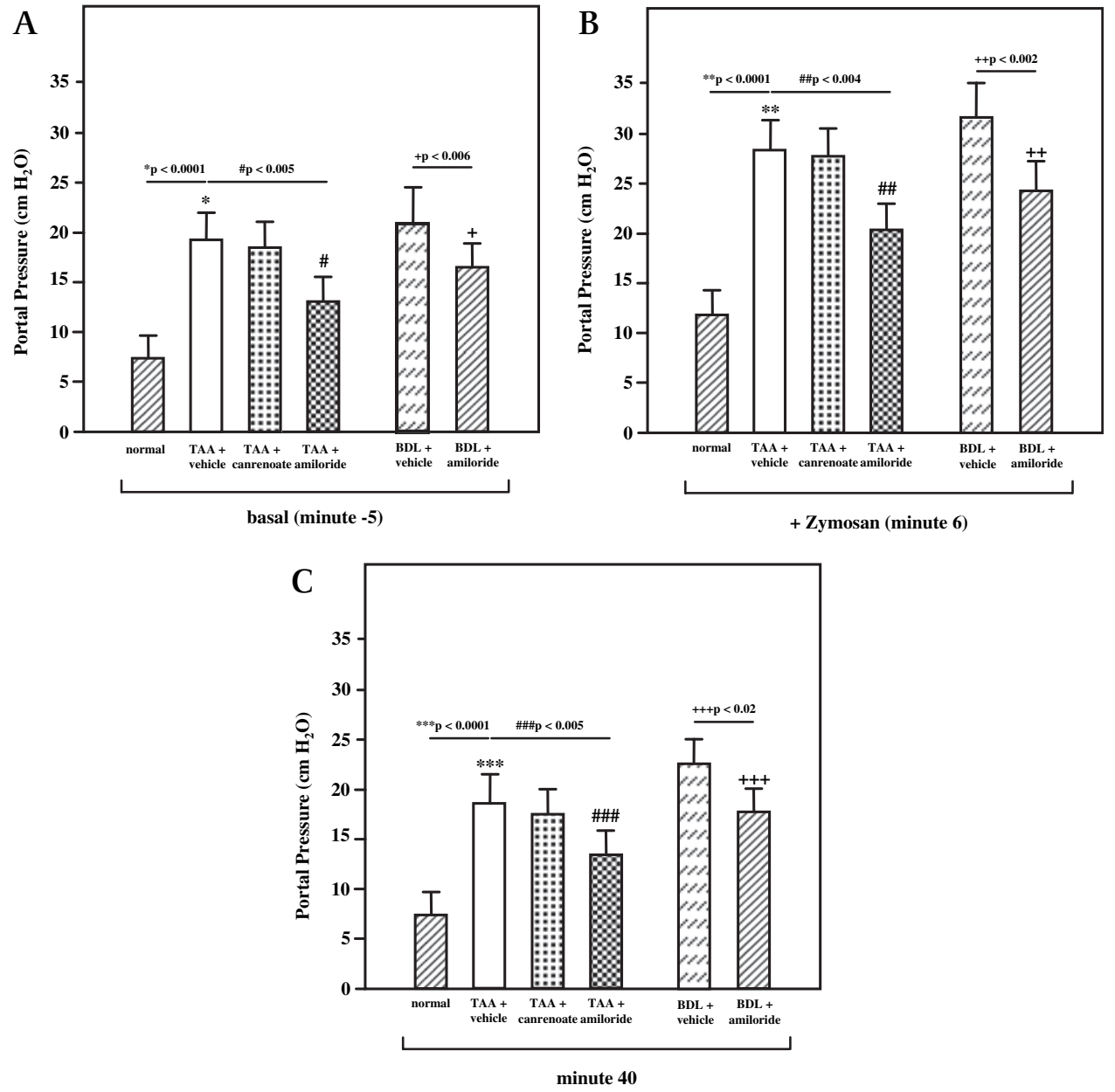

reduced portal pressure at all doses. In contrast, portal pressure decreased only slightly but not significantly by the administration of canrenoate at any dose. A short-term treatment over 3 days confirmed the data of the dose response curve. The amiloride treatment over 3 days lowered both the basal and maximal portal pressure in vivo following $\mathrm{KC}$ activation, but canrenoate altered neither basal nor maximal portal pressure. This is, to our knowledge, the first time that the effects of canrenoate and amiloride on portal pressure have been tested in a model of bile duct ligation or of TAA-induced cirrhosis. The effects of amiloride occurred in both animal models and seemed, therefore, to be independent of the aetiology of the underlying experimental liver disease. the whole body, leads to a sepsis-like syndrome which has been described earlier. ${ }^{10}$ Although the blood pressure decreased, the portal pressure still increased. Altogether, the in vivo experiments supported data obtained from isolated perfused livers.

Effects of canrenoate and amiloride on portal pressure

It has been described that canrenone, the active metabolite of canrenoate and spironolactone, may inhibit the activity of hepatic stellate cells ${ }^{21}$ and lower portal pressure. ${ }^{29} 30$ Therefore, we compared dose-dependent effects of canrenoate and amiloride on portal pressure in vivo. Three different doses were tested for each drug: a dose over the upper limit for therapeutic administration in humans (amiloride $0.5 \mathrm{mg} / \mathrm{kg}$ b.w., canrenoate $5 \mathrm{mg} / \mathrm{kg} \mathrm{b.w.),} \mathrm{a} \mathrm{high} \mathrm{but} \mathrm{feasible} \mathrm{dose} \mathrm{for} \mathrm{treatment} \mathrm{in} \mathrm{humans}$ (amiloride $0.25 \mathrm{mg} / \mathrm{kg} \mathrm{b.w.,} \mathrm{canrenoate} 2.5 \mathrm{mg} / \mathrm{kg} \mathrm{b.w.)} \mathrm{and}$ a generally recommended dose for diuretic treatment in humans (amiloride $0.1 \mathrm{mg} / \mathrm{kg}$ b.w., canrenoate $1 \mathrm{mg} / \mathrm{kg}$ b.w.). Amiloride
Mechanisms involved in reduction of portal pressure by amiloride In addition to our functional experiments, we performed investigations at a molecular level to identify mechanisms that may underlie the reduction of intrahepatic vascular resistance by amiloride. Due to the treatment period of 3 days, any antifibrotic effects expected in long-term treatment ${ }^{21}$ may be excluded in the present study. This was confirmed by Elastica van Giesson staining showing no effect on the extent of fibrosis. The western blot analyses showed that the content of phosphorylated moesin was reduced by amiloride treatment, while the expression of total moesin was not altered. This indicates a decrease of Rho kinase activity by amiloride. Therefore, we speculated that the decrease of intrahepatic vascular resistance in response to amiloride is related to reduced activation of contraction-mediating Rho kinase in cells of intrahepatic 
A

p-moesin

t-moesin

$\beta$-actin

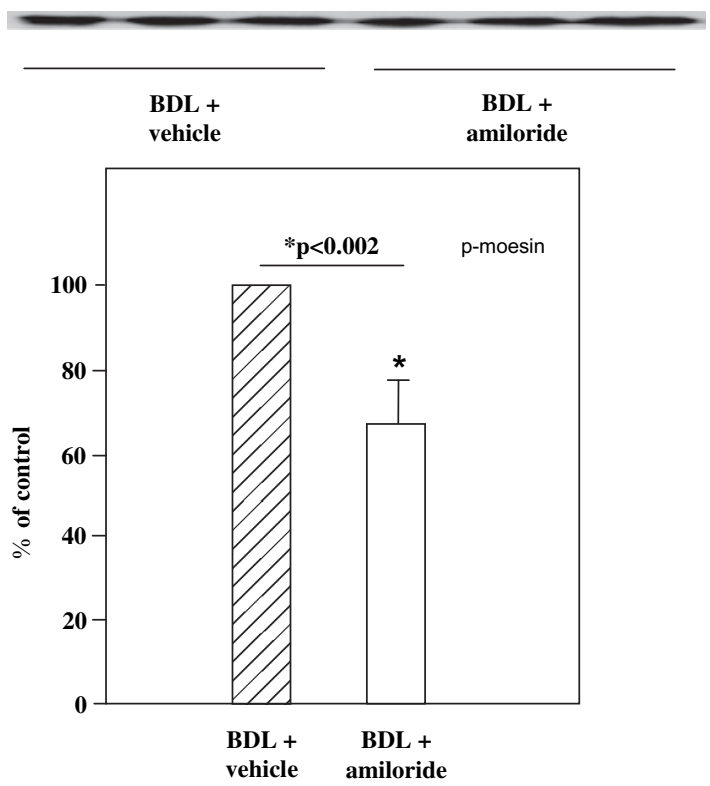

B
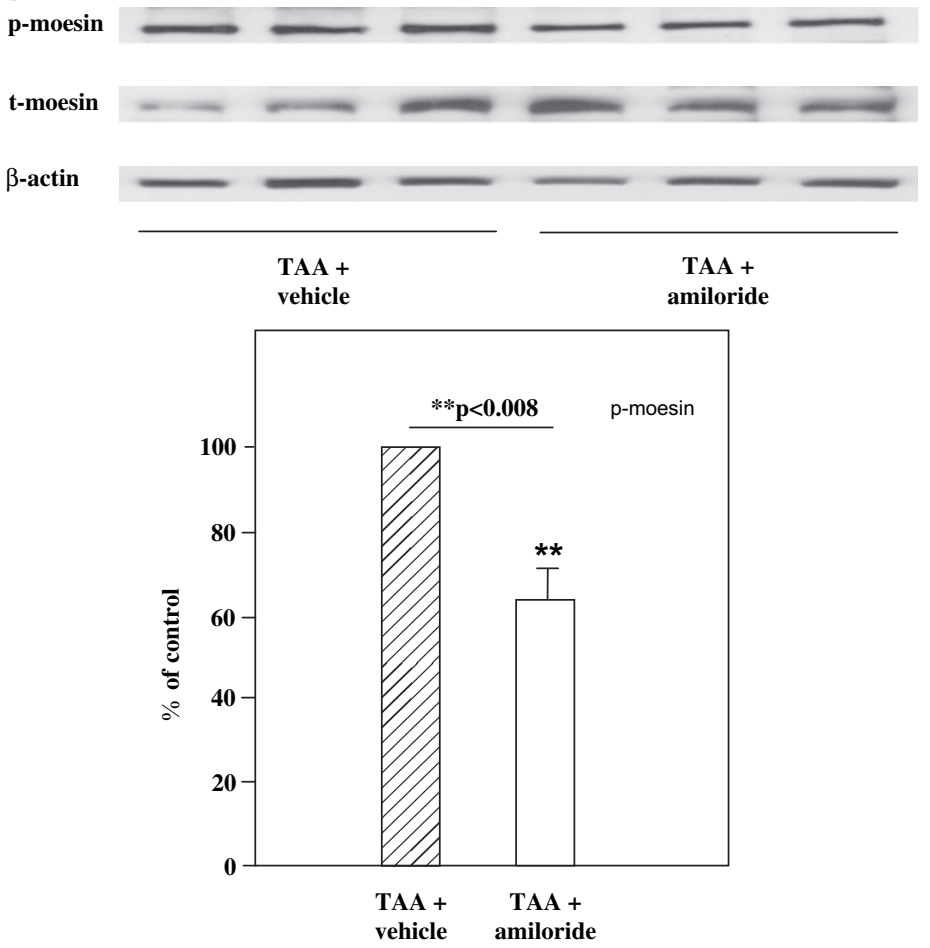

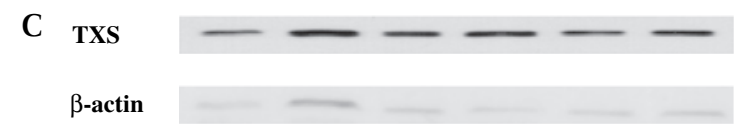

$\beta$-actin

TAA + vehicle

TAA + amiloride

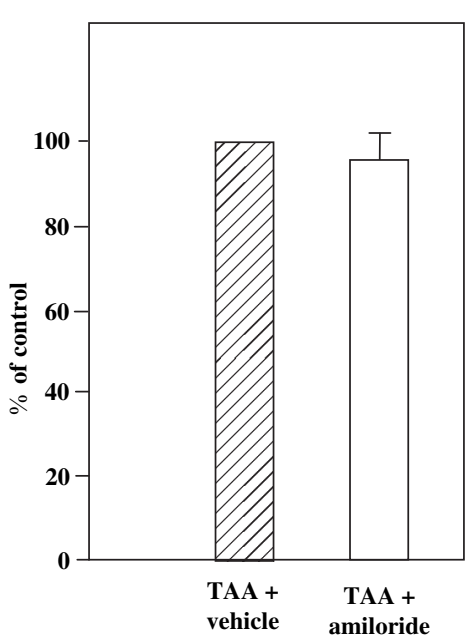

Figure 5 Hepatic phospho-moesin levels and thromboxane synthase expression. (A and B) Effects of amiloride on contractile cells. Phosphorylation of moesin reflects the activity of contraction-mediating Rho kinase in cells such as hepatic stellate cells and myofibroblasts. Treatment of BDL or TAA rats with amiloride for 3 days resulted in decreased hepatic phospho-moesin levels $\left({ }^{*} p<0.002,{ }^{* *} p<0.008\right)$, reflecting reduced activity of Rho kinase in the intrahepatic vasculature. Shown are representative western blots and quantification of all experiments (mean $\pm S D, n=7$ per group). (C) Effects of amiloride on thromboxane synthase expression. The major hepatic cell type expressing thromboxane synthase are Kupffer cells. Treatment of TAA rats with amiloride for 3 days was without effect on hepatic expression of thromboxane synthase. Shown are representative western blots and quantification of all experiments (mean $\pm S D, n=7$ per group).

microvasculature. To further investigate involvement of the hepatic stellate cells, we performed immunohistochemical stainings of liver sections for $\alpha$-SMA. This is widely used as marker for activated hepatic stellate cells. ${ }^{31-34}$ The staining for $\alpha$-SMA indicated a reduced number of activated hepatic stellate cells in the cirrhotic livers after treatment with amiloride.
Western blot analyses confirmed that there was a decrease in the $\alpha$-SMA content by amiloride pre-treatment. However, the TUNEL assay showed no difference for apoptotic cells in vehicleand amiloride-treated animals. Therefore the reduced $\alpha$-SMA content in this experimental setting rather suggests a reduced activity status of the cells with contractile elements. The 
A

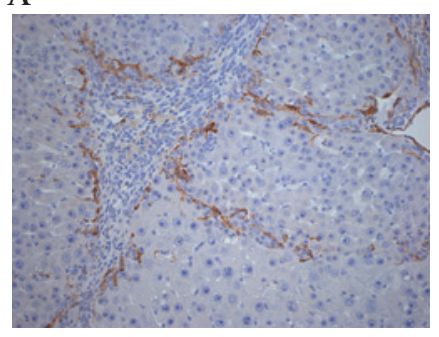

TAA + vehicle, $\alpha$-SMA, $50 x$

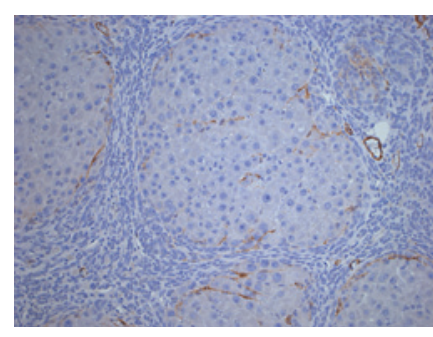

TAA + amiloride, $\alpha-S M A, 50 x$

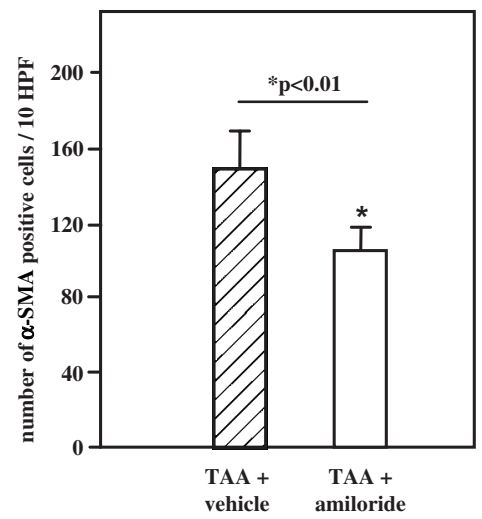

B

$\alpha-S M A$

$\beta$-actin
TAA + amiloride
TAA + vehicle

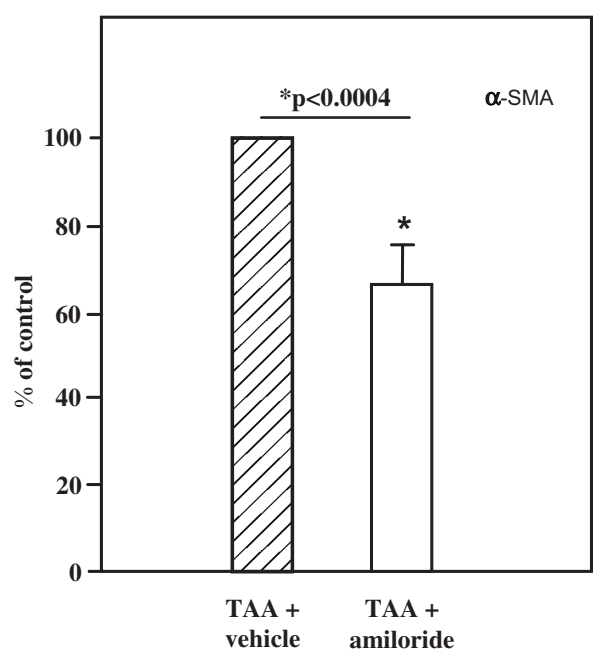

Figure 6 Immunohistochemical staining and western blot analyses of liver sections for $\alpha$-smooth muscle actin ( $\alpha$-SMA). (A) Liver sections of solvent- and amiloride-treated thioacetamide (TAA) rats were stained for $\alpha$-SMA. Treatment of TAA rats with amiloride for 3 days resulted in reduced $\alpha$-SMA-positive cells. Shown are representative microscopic pictures from solvent- and amiloride-treated TAA rats, and quantification of all stained sections ( $n=7$ per group). (B) These findings were confirmed by western blot analyses which showed a reduced content of $\alpha$-SMA in amiloride-treated animals ( $n=7$ per group).

expression of the thromboxane synthase was not altered by amiloride treatment. In the liver, thromboxane synthase is mainly expressed by KCs. ${ }^{10} 12{ }^{35-37}$ This suggests that amiloride reduced intrahepatic vascular resistance via an HSC-dependent mechanism. In addition other mechanisms seem possible. A decreased contraction of myofibroblasts surrounding vascular shunts in cirrhotic septa could be involved in amiloride-induced portal pressure decreases. Major changes in the plasma volume can be excluded due to an almost unaltered mean arterial blood pressure although minor alterations of the plasma volume are feasible. The cardiac output was not measured in these experiments, so that an effect of amiloride on the portal inflow can not be excluded. However, a short treatment period of 3 days or acute application was sufficient to reduce intrahepatic vascular resistance and portal pressure by actions on intrahepatic vasoconstrictor-responsiveness, but without antifibrotic effects.

\section{Clinical considerations}

In the present study, amiloride was administered subcutaneously and intravenously. In clinical practice, amiloride is taken orally. After oral application, amiloride is absorbed in the gut by about $50-70 \%$, but accumulates by repeated doses. Therefore we would expect that the effect is still clear when amiloride is administered orally.

Previously, amiloride was investigated in patients with liver cirrhosis for treatment of ascites, but not yet for portal hypertension. It has been shown that amiloride for treatment of ascites is effective for patients with normal plasma aldosterone level. ${ }^{38}$ Because of the frequency of elevated plasma aldosterone levels in patients with liver cirrhosis, spironolactone seems to be more effective than amiloride to treat ascites in patients with liver cirrhosis. ${ }^{39}$

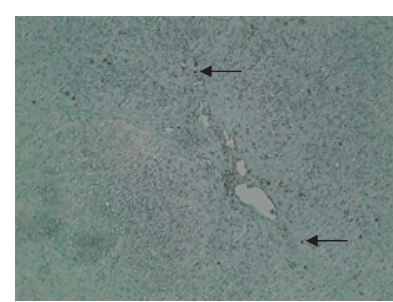

TAA + vehicle, TUNEL, 100x

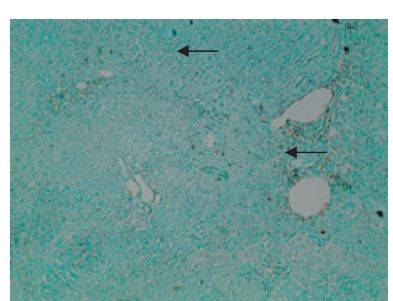

TAA + amiloride, TUNEL, 100x

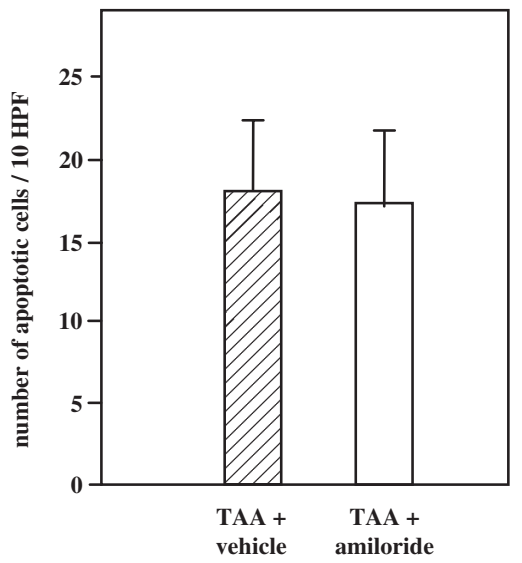

Figure 7 TUNEL assay for detection of apoptotic cells. TUNEL assay was performed as indicated and showed no difference in apoptotic cells for vehicle- or amiloride-treated cells. Shown are representative microscopic pictures from solvent- and amiloride-treated TAA rats, and quantification of all stained sections ( $n=7$ per group). 


\section{Summary box}

Amiloride is well known as a diuretic treatment option for heart diseases and for patients with liver cirrhosis. In addition, it has been described in an experimental study that amiloride has antifibrogenic effects via blockade of the $\mathrm{Na}^{+} / \mathrm{H}^{+}$channel on hepatic stellate cells. The present study showed that amiloride reduced portal pressure via attenuation of intrahepatic vasoconstrictor responsiveness. If this effect could be confirmed by a clinical study, patients with liver cirrhosis and portal hypertension may benefit from amiloride by lowering portal pressure, in addition to its diuretic effect.

The efficacy of spironolocatone or potassium canreonate to lower portal pressure has been investigated in different studies. ${ }^{40-42}$ In one clinical study, spironolactone reduced HVPG by about $18 \%$ in a small group, which included three Child A patients, while no effect was observed in six Child B patients. ${ }^{40}$ The portal pressure decrease observed in the present study was performed in TAA and BDL rats with advanced cirrhosis. This suggests that amiloride may be more effective than spironolactoe or canreonate in advanced cirrhosis. This is confirmed by another clinical study, ${ }^{41}$ where the appearance or progression of oesophageal varices in pre-ascitic cirrhosis was not reduced by potassium canrenoate. In a preliminary study, combination therapy of nadolol plus spironolactone did not increase the efficacy of nadolol alone in prophylaxis of first variceal bleeding. ${ }^{43}$ In our experimental study, canrenoate was associated with a slight but not significant decrease in portal pressure. The effect in our study was slightly less pronounced than in earlier experimental studies. ${ }^{29} 30$

Treatment with amiloride over 3 days in our experimental study lowered the portal pressure by attenuation of intrahepatic responsiveness to vasoconstrictors. Intrahepatic vasoconstriction is also dependent on cirrhosis formation which was not influenced by the treatment over 3 days in the present study. Previous studies observed antifibrogenic effects by amiloride in vivo and in vitro 2021 and by canrenone in vitro. ${ }^{21}$ Therefore both, canrenone and amiloride could influence fibrosis progression, but this was beyond the scope of the present study. In fact, the present study demonstrated that amiloride lowered portal pressure by short term treatment via attenuation of intrahepatic vasocontraction in addition to the antifibrogenic effect which has been described previously by long-term treatment. ${ }^{20}$

\section{CONCLUSIONS}

In conclusion, amiloride is effective in lowering portal pressure while canrenoate had limited potential to lower portal pressure in rat liver cirrhosis. This suggests that amiloride may benefit patients with liver cirrhosis and portal hypertension by lowering portal pressure, in addition to its diuretic effect.

Acknowledgements The authors would like to thank Ingrid Liss and Christoph v. Hesler for their excellent technical assistance. We would like to thank Peter Dirschedl for his support in statistical preparation and analysis of this work. This study is part of the thesis of Christina Hartmann.

Funding This study was supported by grants from the Faculty of Medicine, University of Munich (MolMed and LebMit) and by the Deutsche Forschungsgemeinschaft (DFG, STE 1022/2-11.

Competing interests None.
Ethics approval All animal experiments were approved by the local government, Regierung von Oberbayern, Munich, Germany.

Provenance and peer review Not commissioned; externally peer reviewed.

\section{REFERENCES}

1. Ytting $\mathbf{H}$, Moller S, Henriksen JH, et al. Prognosis in patients with cirrhosis and mild portal hypertension. Scand J Gastroenterol 2006;41:1446-53.

2. Merkel C, Bolognesi M, Sacerdoti D, et al. The hemodynamic response to medical treatment of portal hypertension as a predictor of clinical effectiveness in the primary prophylaxis of variceal bleeding in cirrhosis. Hepatology 2000;32:930-4.

3. Bendtsen F, Krag A, Moller S. Treatment of acute variceal bleeding. Dig Liver Dis 2008;40:328-36.

4. Albillos A, Banares R, Gonzalez M, et al. The extent of the collateral circulation influences the postprandial increase in portal pressure in patients with cirrhosis. Gut 2007:56:259-64.

5. Pinzani M, Vizzutti F. Fibrosis and cirrhosis reversibility: clinical features and implications. Clin Liver Dis 2008;12:901-13, x.

6. Calvaruso V, Maimone $S$, Gatt $A$, et al. Coagulation and fibrosis in chronic liver disease. Gut 2008;57:1722-7.

7. Fernandez M, Semela D, Bruix J, et al. Angiogenesis in liver disease. J Hepatol 2009:50:604-20.

8. Moore K. Endothelin and vascular function in liver disease. Gut 2004;53:159-61

9. Graupera M, March S, Engel P, et al. Sinusoidal endothelial COX-1-derived prostanoids modulate the hepatic vascular tone of cirrhotic rat livers. Am J Physiol Gastrointest Liver Physiol 2005;288:G763-70.

10. Steib CJ, Gerbes AL, Bystron M, et al. Kupffer cell activation in normal and fibrotic livers increases portal pressure via thromboxane A2. J Hepatol 2007;47:228-38.

11. Wiest R, Groszmann RJ. The paradox of nitric oxide in cirrhosis and portal hypertension: too much, not enough. Hepatology 2002:35:478-91.

12. Miller AM, Masrorpour M, Klaus C, et al. LPS exacerbates endothelin-1 induced activation of cytosolic phospholipase $\mathrm{A} 2$ and thromboxane $\mathrm{A} 2$ production from Kupffer cells of the prefibrotic rat liver. J Hepatol 2007:46:276-85.

13. Lee CH, Loureiro-Silva MR, Abraldes JG, et al. Decreased intrahepatic response to alpha1-adrenergic agonists in lipopolysaccharide-treated rats is located in the sinusoidal area and depends on kupffer cell function. J Gastroenterol Hepatol 2007;22:893-900.

14. Steib CJ, Gerbes AL. Signaling pathways in liver diseases: kupffer cells. In: Dufour J-F, Clavien P-A, eds. Signaling pathways in liver diseases. Heidelberg: Springer Verlag, 2009

15. Zhou Q, Hennenberg M, Trebicka J, et al. Intrahepatic upregulation of RhoA and Rhokinase signalling contributes to increased hepatic vascular resistance in rats with secondary biliary cirrhosis. Gut 2006;55:1296-305.

16. Hennenberg M, Trebicka J, Sauerbruch T, et al. Mechanisms of extrahepatic vasodilation in portal hypertension. Gut 2008;57:1300-14.

17. Trebicka J, Hennenberg M, Laleman W, et al. Atorvastatin lowers portal pressure in cirrhotic rats by inhibition of RhoA/Rho-kinase and activation of endothelial nitric oxide synthase. Hepatology 2007;46:242-53.

18. Hennenberg M, Biecker E, Trebicka J, et al. Defective RhoA/Rho-kinase signaling contributes to vascular hypocontractility and vasodilation in cirrhotic rats. Gastroenterology 2006;130:838-54.

19. Hennenberg M, Trebicka J, Stark C, et al. Sorafenib targets dysregulated Rho kinase expression and portal hypertension in rats with secondary biliary cirrhosis. $\mathrm{Br} \mathrm{J}$ Pharmacol 2009;157:258-70.

20. Benedetti A, Di Sario A, Casini A, et al. Inhibition of the $\mathrm{Na}(+) / \mathrm{H}(+)$ exchanger reduces rat hepatic stellate cell activity and liver fibrosis: an in vitro and in vivo study. Gastroenterology 2001;120:545-56.

21. Caligiuri A, De Franco RM, Romanelli RG, et al. Antifibrogenic effects of canrenone an antialdosteronic drug, on human hepatic stellate cells. Gastroenterology 2003; 124:504-20.

22. Laleman W, Vander El, Zeegers $\mathrm{M}$, et al. A stable model of cirrhotic portal hypertension in the rat: thioacetamide revisited. Eur J Clin Invest 2006;36:242-9.

23. Bilzer M, Paumgartner G, Gerbes AL. Glutathione protects the rat liver against reperfusion injury after hypothermic preservation. Gastroenterology 1999;117:200-10.

24. Bilzer M, Baron A, Schauer R, et al. Glutathione treatment protects the rat liver agains injury after warm ischemia and Kupffer cell activation. Digestion 2002;66:49-57.

25. Schauer RJ, Gerbes AL, Vonier D, et al. Induction of cellular resistance against Kupffer cell-derived oxidant stress: a novel concept of hepatoprotection by ischemic preconditioning. Hepatology 2003;37:286-95.

26. Hennenberg $\mathbf{M}$, Trebicka J, Biecker $\mathbf{E}$, et al. Vascular dysfunction in human and rat cirrhosis: role of receptor-desensitizing and calcium-sensitizing proteins. Hepatology 2007:45:495-506.

27. Van de Casteele M, Hosli M, Sagesser $\mathrm{H}$, et al. Intraportal administration of glyceryl trinitrate or nitroprusside exerts more systemic than intrahepatic effects in anaesthetised cirrhotic rats. J Hepatol 1999;31:300-5.

28. Haussinger D, Brodde OE, Starke K. Alpha-adrenoceptor antagonistic action of amiloride. Biochem Pharmacol 1987;36:3509-15.

29. Oberti F, Pilette $\mathrm{C}$, Rifflet $\mathrm{H}$, et al. Effects of simvastatin, pentoxifylline and spironolactone on hepatic fibrosis and portal hypertension in rats with bile duct ligation. J Hepatol 1997;26:1363-71. 
30. Van de Casteele M, Van Roey G, Nevens F, et al. Effects of varying doses of spironolactone without and with nitrates on portal vein pressure and kidney function in partial portal vein ligated rats. Hepatology 1996;24:1492-6.

31. Asahina K, Tsai SY, Li P, et al. Mesenchymal origin of hepatic stellate cells, submesothelial cells, and perivascular mesenchymal cells during mouse liver development. Hepatology 2009;49:998-1011.

32. Cassiman D, Libbrecht L, Desmet V, et al. Hepatic stellate cell/myofibroblast subpopulations in fibrotic human and rat livers. J Hepatol 2002;36:200-9.

33. Cassiman D, Roskams T. Beauty is in the eye of the beholder: emerging concepts and pitfalls in hepatic stellate cell research. J Hepatol 2002;37:527-35.

34. Mabuchi A, Mullaney I, Sheard PW, et al. Role of hepatic stellate cell/hepatocyte interaction and activation of hepatic stellate cells in the early phase of liver regeneration in the rat. J Hepatol 2004;40:910-16.

35. Nanji AA, Rahemtulla A, Maio L, et al. Alterations in thromboxane synthase and thromboxane A2 receptors in experimental alcoholic liver disease. J Pharmacol Exp Ther 1997;282:1037-43

36. Yokoyama Y, Nimura Y, Nagino M, et al. Role of thromboxane in producing hepatic injury during hepatic stress. Arch Surg 2005;140:801-7.
37. Bilzer M, Roggel F, Gerbes AL. Role of Kupffer cells in host defense and liver disease. Liver Int 2006;26:1175-86.

38. Angeli $\mathbf{P}$, Dalla PM, De Bei E, et al. Randomized clinical study of the efficacy of amiloride and potassium canrenoate in nonazotemic cirrhotic patients with ascites. Hepatology 1994;19:72-9.

39. Moore KP, Wong F, Gines $\mathrm{P}$, et al. The management of ascites in cirrhosis: report on the consensus conference of the international ascites club. Hepatology 2003;38:258-66

40. Sugano S, Kawafune T, Okajima T, et al. Chronic splanchnic hemodynamic effects of spironolactone with unrestricted sodium diet in patients with compensated cirrhosis. Dig Dis Sci 1998;43:893-7.

41. Bolondi L, Piscaglia F, Gatta A, et al. Effect of potassium canrenoate, an antialdosterone agent, on incidence of ascites and variceal progression in cirrhosis. Clin Gastroenterol Hepatol 2006;4:1395-402.

42. Klein CP. [Spironolactone in the treatment of portal hypertension in liver cirrhosis. A new therapeutic principle?]. Dtsch Med Wochenschr 1985:110:1774-6.

43. Abecasis R, Kravetz D, Fassio E, et al. Nadolol plus spironolactone in the prophylaxis of first variceal bleed in nonascitic cirrhotic patients: a preliminary study. Hepatology 2003:37:359-65.

\section{Editor's quiz: GI snapshot}

\section{ANSWER}

From the question on page 807

Pathological evaluation of the resected tumour revealed a tubular adenoma with mild glandular dysplasia (figure 1). Small bowel adenomas are classified histologically as tubular, tubulovillous or villous. ${ }^{1}$ They have more frequently been described in the duodenum than in the jejunum and the ileum. ${ }^{2}$

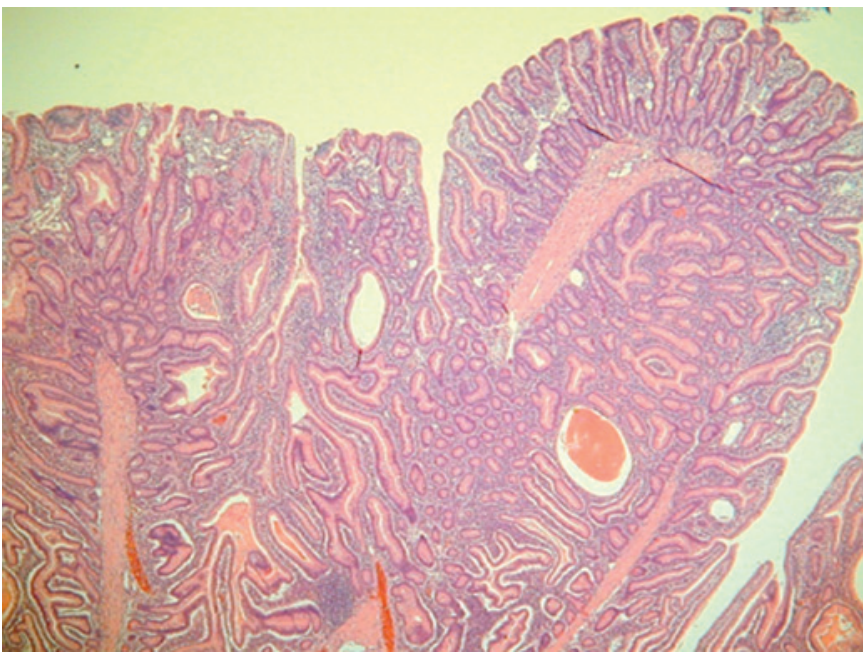

Figure 1 Pathological examination of the resected tumour confirmed the diagnosis of a tubular adenoma with mild glandular dysplasia $(\mathrm{H} \& \mathrm{E}, \times 20)$.
They may develop as single or multiple lesions, both sessile and pedunculated. Haemorrhage, obstruction and intussusception are the most common complications. ${ }^{2}$ Rarely, they may be associated with malignant degeneration. ${ }^{1}$ Preoperative diagnosis of this tumour is difficult. DBE and CE are useful modalities in detecting small bowel tumours, including adenomas. Small bowel adenomas should be removed because of the risk of malignancy or complication; conventionally this meant surgical resection. ${ }^{3}$ Endoscopic polypectomy is an alternative method despite a high risk of complications such as haemorrhage or perforation. ${ }^{4}$ Endoloop-assisted polypectomy of large gastrointestinal tumours, mostly lipomas, has been reported to be safe and efficacious. ${ }^{5}$ To date, this is the first case of a large jejunal adenoma that was successfully treated with an endoloopassisted polypectomy using DBE.

Gut 2010;59:836.doi:10.1136/gut.2009.184309a

\section{REFERENCES}

1. Sellner F. Investigations on the significance of the adenoma-carcinoma sequence in the small bowel. Cancer 1990;66:702-15.

2. Levine BA, Kaplan BJ. Polyps and polypoid lesions of the jejunum and ileum: clinical aspects. Surg Oncol Clin N Am 1996;5:609-19.

3. Minardi AJ Jr, Zibari GB, Aultman DF, et al. Small-bowel tumors. J Am Coll Surg 1998:186:664-8.

4. May A, Nachbar L, Pohl J, et al. Endoscopic interventions in the small bowel using double balloon enteroscopy: feasibility and limitations. Am J Gastroenterol 2007:102:527-35.

5. Koo J, Kaffes A. Endoscopic resection of large colonic lipomas assisted by a prototype single-use Endoloop device. Endoscopy 2006;38:644-7. 


\section{GUT Amiloride reduces portal hypertension in rat liver cirrhosis}

Christian J Steib, Martin Hennenberg, Frigga Beitinger, et al.

Gut 2010 59: 827-836

doi: 10.1136/gut.2009.197756

Updated information and services can be found at:

http://gut.bmj.com/content/59/6/827.full.html

\begin{tabular}{|c|c|}
\hline & These include: \\
\hline References & $\begin{array}{l}\text { This article cites } 42 \text { articles, } 7 \text { of which can be accessed free at: } \\
\text { http://gut.bmj.com/content/59/6/827.full.html\#ref-list-1 }\end{array}$ \\
\hline & $\begin{array}{l}\text { Article cited in: } \\
\text { http://gut.bmj.com/content/59/6/827.full.htmI\#related-urls }\end{array}$ \\
\hline $\begin{array}{l}\text { Email alerting } \\
\text { service }\end{array}$ & $\begin{array}{l}\text { Receive free email alerts when new articles cite this article. Sign up in } \\
\text { the box at the top right corner of the online article. }\end{array}$ \\
\hline $\begin{array}{r}\text { Topic } \\
\text { Collections }\end{array}$ & $\begin{array}{l}\text { Articles on similar topics can be found in the following collections } \\
\text { Cirrhosis ( } 282 \text { articles) } \\
\text { Pancreas and biliary tract ( } 1825 \text { articles) }\end{array}$ \\
\hline
\end{tabular}

Notes

To request permissions go to:

http://group.bmj.com/group/rights-licensing/permissions

To order reprints go to:

http://journals.bmj.com/cgi/reprintform

To subscribe to BMJ go to:

http://group.bmj.com/subscribe/ 